\title{
Laparoscopic Hysterectomy Versus Abdominal Hysterectomy of Enlarged Uterus
}

\section{Bassem A Islam}

Department of Obstetrics and Gynecology, Faculty of Medicine, Ain Shams University, Cairo, Egypt

Corresponding Author: Dr Bassem A Islam, Lecturer in Department of Obstetrics and Gynecology, Faculty of Medicine, Ain Shams University, Cairo. Egypt.

Received date: December 16, 2019; Accepted date: January 02, 2020; Published date: January 07, 2020

Citation: Bassem A Islam. (2020) Laparoscopic Hysterectomy versus Abdominal Hysterectomy of Enlarged Uterus. J Women Health Care Issues, 3(1); Doi:10.31579/2642-9756/018

Copyright: () 2020 Bassem A Islam, This is an open access article distributed under the Creative Commons Attribution License, which permits unrestricted use, distribution, and reproduction in any medium, provided the original work is properly cited.

\begin{abstract}
:
This prospective interventional to assess feasibility of total laparoscopic hysterectomy (LH) for uteri weighing 280 gm or more. The study included 120 patients divided to 60 patient conducted total laparoscopic hysterectomies and 60 patients conduct total abdominal hysterectomy as standard method.

Full history taking, gynecologic examination and ultrasound examination were done to all patients. The following data were collected from every patient in all groups: Age, BMI, uterine weight, Operative time, Estimated intraoperative blood loss, Preoperative hemoglobin and postoperative hemoglobin deficit 12 hours after surgery, intraoperative and Post-operative complications, Time to resumption of bowel movements to normal, Length of hospital stay.

The most common indication among our patients was fibroid uterus while adenomyosis came second. All operations were performed by the same surgeons and using the same technique.

We observe BMI is not considering as obstacle in laparoscopic group with advancement of anesthesia and sealing system.

The mean operating time was slightly but not significally lower in laparoscopic hysterectomy with highly significant difference in the estimated blood loss in favor of laparoscopic group.

The total incidence of intra-operative and postoperative complication of patient submitted to laparoscopic hysterectomy lower than conventional hysterectomy group but not statically significantly. There was significant difference in pain scoring, earlier bowel movement and hospital stay in the arm of laparoscopic group.

Conclusion: The total laparoscopic hysterectomy of enlarged uterus is a safe and reasonable alternative procedure to traditional abdominal hysterectomy in terms of operative and postoperative short-term outcomes.

Key Words: laparoscopic hysterectomy; versus abdominal hysterectomy
\end{abstract}

\section{Introduction}

Hysterectomy is the most common major gynecological operation performed in the world, that is often performed for symptomatic benign diseases, including menorrhagia, fibroids, pelvic pain, and uterine prolapse are responsible for more than $70 \%$ of indications for hysterectomy [1].

There is no universal agreement on the best technique for hysterectomy [2] and the route of choice (conventional open surgery, laparoscopy or vaginal surgery) depends on clinical and technical factors, such as uterine weight and previous vaginal deliveries, as well as on the preference of the surgeon

[3].

The removal of an extremely large uterus represents a challenge to the surgeon regardless of the surgical approach and technique used. Giant myomas obstruct the pelvis and make the uterus extremely difficult to mobilize and manipulate, thus reducing the possibility to visualize the surrounding anatomic structures and partially or totally impairing the surgeon's ability to correctly develop the spaces. There are no clear guidelines about large uteri, and the literature is vague regarding the best surgical option in these cases [4].Large uteri also increase complications and morbidities, such as prolonged operation time, excessive blood loss from retrograde bleeding [5] and high rates of blood transfusion and laparoconversion. With time, surgical techniques have progressed, and laparoscopic instruments have improved, both of which have led to hysterectomies for large uteri being performed by laparoscopy safely and effectively [6].

Specimen can be removed more efficiently by many techniques for volume reduction, including transvaginal volume reduction, laparoscopic morcellation, a combination of vaginal and laparoscopic procedures and mini-laparotomy [7].

\section{Aim of the work:}

The aim of this study was to assess feasibility of laparoscopic hysterectomy (LH) for uteri weighing 280 gm or more and compare this technique with conventional hysterectomy. 


\section{Patients and Methods:}

This study was prospective interventional clinical study.

From January 2016 and August 2019. The study took place in Ain Shams University hospital and patients were recruited from Ain Shams Gynecology clinic. Sample size was calculated by open EPI to be 120 cases with confidence level $95 \%$ and power of test $80 \%$.

\section{Inclusion criteria for cases:}

a) Women candidate for hysterectomy with benign lesion.

b) Uterine weight more than $280 \mathrm{gm}$.

\section{Exclusion criteria:}

a) Any case with malignant lesion.

b) Contraindications to laparoscopy such as multiple previous surgeries or cardio-vascular disorders.

This study included 120 patients scheduled to undergo total hysterectomy and bilateral salpingectomy with or without bilateral ooophorectomy. they were divided into 2 groups.

Conventional hysterectomy group (A): (60 patients) will undergo abdominal hysterectomy using conventional sutures.

Laparoscopic hysterectomy group (B): (60 patients) will undergo laparoscopic hysterectomy using LigaSure.

\section{Methods:}

Method of intervention was adopted according to patient's desire. Appropriate informative consent was obtained from the patient after a thorough explanation and description of the planned procedure, its potential risks and benefits, and the possibility of conversion to laparotomy in the laparoscopic group. Patients are informed that general anesthesia will be used with proper explanation of the procedure and its potential risks by the anesthesiologist.

Full history taking, gynecologic examination and ultrasound examination were done to all patients.

The following data were collected from every patient in all groups:

- $\quad$ Personal history (Age, marital status).

- Obstetric and gynecological history (parity, menopausal status).

- Medical history (diabetes mellitus, cardiac disease).

- $\quad$ Surgical history (previous CS).

- Ultrasound examination of the pelvis: uterus and adnexa

Combined transabdominal and transvaginal ultrasound was performed with a $3.5 \mathrm{mHz}$ and $7.5 \mathrm{mHz}$ respectively to determine all 3 uterine dimensions.

The uterine length $(\mathrm{L})$ was the distance between the external cervical os to the dome of the fundus; the maximum width (W) and anteroposterior (AP) diameter were taken perpendicular to the axis of the uterine length. The ultrasound estimated uterine weight (UWT) was derived from the algebraic formula by Kung and Chang 1996 expressed in weights and measurements: weight $(\mathrm{g})=50+(4 / 3 \times \pi \times \mathrm{L} / 2 \times \mathrm{W} / 2 \times \mathrm{AP} / 2)$, this formula was further simplified to: weight $(\mathrm{g})=\mathrm{L} \times \mathrm{W} \times \mathrm{AP} \times 0.52$ (8).
- General examination (height and weight to calculated BMI).

- Operative details (Operative time, intraoperative complications like urinary or intestinal injuries, Estimated intraoperative blood loss, Preoperative hemoglobin and postoperative hemoglobin deficit 12 hours after surgery)

- Postoperative details (Time to resumption of bowel movements to normal, length of hospital stay, postoperative complications).

- NB: EstimatDuring laparotomy, the fully soaked laparotomy pad $(30 \times 30 \mathrm{~cm})$ means about $100-150 \mathrm{cc}$ blood loss and the soaked surgical sponge $(4 \times 4 \mathrm{~cm})$ means about $10 \mathrm{cc}$ and the amount of blood in suction container is added.

During laparoscopy the amount of blood loss was estimated by the amount in the suction container after subtracting the amount of fluid used for washing intraoperative blood loss measured.

All patients are advised to be fasting for 12 hours before surgery. Two fleet enemata are done; one the night before and one 2 hours before operation.

Routine preoperative tests were done for every patient including: CBC, coagulation profile, FBS, hepatitis markers screening, liver and kidney function tests and ECG. Patients with other medical problems need further evaluation by general medicine doctor who may order other laboratory tests as required.

General anesthesia is used and prophylactic antibiotics are given in the form of 2 grams cefotaxime which is repeated as one gram 12 hours after surgery.

All the operations were performed by at least one of the consultants included as supervisors in this study.

After the operation, all patients are given analgesia in the form of meperidine (pethidine) $50 \mathrm{mg}$ injection once plus diclophenac sodium (Voltaren $75 \mathrm{mg}$ ampoule) intramuscularly twice 12 hours apart. Further analgesia is required in some cases. Oral fluids begin as soon as possible after recording bowel movements followed by semisolid fluids. Patients are allowed to go home when ambulatory, passing urine and gas normally without complications. Patients are provided after discharge with a telephone number that is available 24 hours a day. Follow-up visits are scheduled after one week, then after one month.

Thromboprophylaxis in the form of 40-60 mg Enoxaparin (Clexane) is given 6-12 hours postoperatively as SC injections, then every 24 hours for 3-5 days.

In the laparoscopy group, the operating table is designed to allow a deep Trendelenburg position. The patients are placed in padded Allen stirrups to provide good support and positioning. After thighs are slightly abducted, semi flexed, a uterine manipulator is fixed. In this study, Clermont-Ferrand manipulator is used.

Surgical technique:

\section{Groups A (abdominal hysterectomy with conventional sutures):}

After general anesthesia, a Foley catheter is fixed within the bladder and the patient is put in Trendelenburg position. A transverse incision is made 
into the pubic hairline including skin and subcutaneous fat until reaching the anterior rectus fascia.

The fat is cleared from the midline superiorly and inferiorly to expose approximately $5-6 \mathrm{~cm}$ of fascia in the vertical axis. The anterior rectus fascia is cut in a Transverse. The rectus muscles are separated, exposing the fascia transversalis and the peritoneum. The peritoneum is entered digitally or by scissors.

The uterus and the adnexa are brought outside the abdominal wall using the index and middle fingers as well as the thumb of the left hand and sometimes either a strong traction suture in the uterine fundus or via two long Kocher clamps lateral to the corpus. Two long, narrow abdominal retractors are used. Packing of the intestine is done.

The round and infundibulopelvic ligaments are secured and cut using either clamps or sutures. The uterine vessels are clamped, divided, ligated. The bladder is mobilized while the cardinal and uterosacral ligaments are divided. The specimen is cut away from vaginal cuff which is closed via open cuff or closed cuff techniques. The abdominal wall is closed as usual with the pelvic and parietal peritoneum unclosed and the rectus muscles are approximated in the midline via 2 to 3 interrupted sutures. The rectus sheath was then closed with vicryl No.1 running sutures. Subcutaneous fat was closed only if it is $>2 \mathrm{~cm}$ thickness using Vicryl No.2/0 sutures. The skin was closed by applying subcuticular non-absorbable polypropylene sutures.

\section{Group B (laparoscopic group):}

Routine laparoscopic equipment that is essential for performing a successful laparoscopic hysterectomy includes:

- Standard laparoscopic tower containing a high-flow $\mathrm{CO} 2$ insufflator, camera and a light source.

- An operating table with leg stirrups and capability of placing the patient in steep Trendelenburg position is essential.

- Some kind of bleeding control instrument such as, bipolar and unipolar electricity generator, LigaSure vessel sealing instrument.

- A uterine manipulator capable of extreme anteversion and movement of the uterus in an $\operatorname{arc}$ of $45^{\circ}$ to the right and left is important. In this study, Clemont Ferrand manipulator was used.

- Two good laparoscopic graspers with long jaws for grasping and manipulating the uterus, adnexal structures and bowel.

- Suction irrigator is essential to clear out the smoke if unipolar or bipolar energy is used and to remove the blood and blood clots.

- Ancillary instruments such as laparoscopic needle holders.

- Force Triad which is vessel sealing machine and the most recent ligaSure vessel sealing machine, we used LigaSure atlas instrument $10 \mathrm{~mm}, 5 \mathrm{~mm}$ and valley lab blending mode.

\section{Trocar placement:}

We routinely place a Veress needle in the lower edge of the umbilicus. Sometime we enter peritoneal cavity through palmer point in case of previous lower abdominal surgery after insertion of rayel and exclude splenomegaly also to avoid injury of enlarged uterus we enter peritoneal cavity in point between umbilicus and xyphoid process lee huang pointpoint . We then insufflate to $20 \mathrm{mmHg}$ prior to placement of any trocars. A $10-12 \mathrm{~mm}$ trocar is then placed through a vertical lower intraumbilical incision for insertion of the zero-degree telescope (Karl Storz, Tuttlingen, Germany). Two additional $5 \mathrm{~mm}$ trocars are then placed into the peritoneal cavity. This pair were placed lateral to the inferior epigastric vessels approximately two fingerbreadths above the pubis. the third one was $12 \mathrm{~mm}$ and put in the suprapubic region. In some cases, we used only two $(10 \mathrm{~mm})$ lateral ports without suprapubic one.

\section{Identification of the ureters:}

The ureters should be identified prior to securing any supporting structures to the uterus. In most cases the ureters are visible through the peritoneum. It lies on the medial peritoneal leaf of the broad ligament.

\section{Securing the round ligaments:}

The round ligaments can easily be desiccated by using ligaSure instrument. The uterus is deviated to the left by the manipulator and the assistant uses a grasper to place the round ligament under tension. The round ligament is coagulated and cut in the middle of the ligament with the coagulating instrument introduced from the ipsilateral side.

\section{Securing infundibulopelvic and uterine-ovarian ligaments:}

For women who want to preserve their ovaries, the uterine-ovarian ligaments and Fallopian tubes were sealed and cut medial to the ovary using ligaSure atlas instrument $10 \mathrm{~mm}$. but if we want to remove the ovaries we cut the infundibulopelvic ligament itself taking care of the course of the ureter.

\section{Creation of the bladder flap:}

An assistant retroverts the uterus and pushes it cephalad using the manipulator. The upper junction of the vesico-uterine peritoneal fold is distinguished as a white line. Identification of the white line is important because, cephalad to the white line, the peritoneum is attached tightly to the uterus. Below this demarcation the peritoneum is loosely attached to the cervix and can be easily dissected away. The dome of the bladder is approximately $2 \mathrm{~cm}$ to $2.5 \mathrm{~cm}$ below the white line.

Using a grasper, the vesicouterine fold is placed under traction. A transverse incision is made just below the white line and the bladder is dissected away from the lower uterine segment and cervix using a peace of sponge on a grasper. In the right tissue plane, the dissection should be relatively bloodless. The middle band of loose connective tissue is the vesico-cervical ligament. This ligament does not contain blood vessels and can be easily divided. Laparoscopic scissors with electroenergy can be used to coagulate any small incidental bleeders during dissection. The lateral bands of connection on both sides of the cervix are bladder pillars. The bladder pillars contain blood vessels and are desiccated prior to dissection.

Dissection of the bladder laterally helps pull the ureters away from the cervix. To achieve this, the bladder peritoneum is incised to the level of the round ligament. Dissection is continued in the avascular plane and the bladder is pushed caudally over the cervix to its junction with the anterior fornix of the vagina.

\section{Securing the uterine arteries:}

The broad ligaments on both sides are opened downward and towards the cervix, skeletonizing the uterine vessels. Once the uterine vessels are skeletonized they can be sealed laterally using LigaSure atlas instrument 
$10 \mathrm{~mm}$. With meticulous dissection, the uterine vessels can be identified at the level of the ureteric canal as it crosses above the ureter. Knowledge of the course of the ureter is essential at this point to avoid injury. the uterine vessels can be secured medially as they enter the uterine body.

After dealing with the uterine artery, the manipulator is used to push the uterus to the left side during grasping and cutting the Mackenrodet's ligament on the right and vice versa. This is done using LigaSure instrument.

After that, we use the Valley laparoscopic hook or unipolar hook to open the vagina, we open the vagina anteriorly against the hard part of the manipulator and we move it laterally and posteriorly carefully to open the cuff laterally, then posteriorly. For fear of loss of pneumoperitoneum, we use a big sponge in a glove to pack the vagina tightly and surround the manipulator. Then, we remove the uterus vaginally as one part or after morcellation. The surgeon put it in the opening and by a Vulsellum forceps we catch it vaginally and remove it.

After removing the uterus, we do underwater examination and for this purpose, we insufflate the peritoneum again, then irrigate the peritoneal cavity with 1000-1500 cc saline, and inspect carefully all the pedicles and the vaginal vault, any bleeding point was controlled using bipolar forces or LigaSure instrument. The vault is either left opened or closed laparoscopically.

We remove all the trocars under vision. $\mathrm{CO} 2$ was allowed to escape gradually, and then the last trocar is removed under vision. Lastly, we close the skin using non-absorbable silk suture which is removed after 7 days.

\section{Statistical analysis}

Statistical analysis was performed using the Statistical Package for Social Science for Windows (SPSS, Inc., Chicago, IL) version 20 (10).

\section{Level significance:}

For all above mentioned statistical tests done, the threshold of significance is fixed at $5 \%$ level ( $\mathrm{p}$-value). A $\mathrm{P}$ value $<0.05$ was considered statistically significant. Independent $t$ test was used for statistical analysis, Variables with normal distribution were expressed as mean and $95 \% \mathrm{CI} \pm$ standard deviation.

Results:

During the study period started from January 2016 to December 2019, a total of 120 patients underwent hysterectomy for uteri more than $280 \mathrm{gm}$. As a consequence, 60 patients were included in conventional hysterectomy group and 60 patients in laparoscopic hysterectomy group.

The $\mathrm{p}$ value in body mass index as shown in table 1 was significant with laparoscopic hysterectomy group $(34.3 \pm 1.3 \mathrm{~kg} / \mathrm{m} 2)$ in comparison to conventional hysterectomy group $(29.8 \pm 1.4 \mathrm{~kg} / \mathrm{m} 2)$. In other side no difference was found between the two groups in term of age, parity and previous abdominal surgery.
All patients were operated in this study only benign condition. Including fibroid uterus, endometrial hyperplasia, dysfunctional uterine bleeding not responding to medical treatment and suspected adenomyosis as listed in table [2]. Fibroid uterus represented $70 \%$ in conventional hysterectomy group, $66.6 \%$ in laparoscopic hysterectomy group. Suspected adenomyosis represented $10 \%$ in conventional hysterectomy group $16.6 \%$ in laparoscopic hysterectomy group. Dysfunctional Uterine Bleeding (DUB) represented $13.3 \%$ in conventional hysterectomy group, $6.6 \%$ in laparoscopic hysterectomy group. Also, endometrial hyperplasia represented $6.6 \%$ in conventional hysterectomy group, $10 \%$ in laparoscopic hysterectomy group.

There are no difference was found between the two groups in ultrasound variables in both group as described in Table 3.

As shown in table (4) there was highly significant difference in the estimated blood loss among the two groups with group of laparoscopic hysterectomy having the least blood loss $(110.1 \pm 30.8 \mathrm{ml})$ in comparison to groups of conventional hysterectomy $(170.3 \pm 54.4)$. Also, there was significant difference in hemoglobin drop between groups of laparoscopic hysterectomy $(0.7 \pm 0.2 \mathrm{gm} / \mathrm{dl})$ to groups of conventional hysterectomy $(1.4 \pm 0.9 \mathrm{gm} / \mathrm{dl})$.

There is no signifance difference in intraoperative blood transfusion and mean operative time between both groups. As regard intraoperative and postoperative complication of patient submitted to laparoscopic hysterectomy for enlarged uterus .There were one patient of ureteral injury (discovered day 5 postoperative with leakage of urine per vagina, ureteric stent inserted by cystoscopy and removed after 2 months with complete healing), abdominal wall hematoma (developed at site of right lateral port with close follow up and resolve spontaneously) and postoperative febrile morbidity however in conventional hysterectomy group one patient had bladder injury (During pushing the bladder flap downwards, the injury occurred and repair was done) ileus and vaginal stump infection ,three patient of wound seroma and infection and five patient with postoperative febrile morbidity. The total incidence of intraoperative and postoperative complication of patient submitted to laparoscopic hysterectomy lower than conventional hysterectomy group but not statically significantly as show in table [4].

As shown in table (5), there was a significant difference in the pain score; using the revised faces pain scale; among the two groups with the highest pain score being observed in conventional hysterectomy group $(5.2 \pm 1.1)$ versus laparoscopic hysterectomy group $(3.8 \pm 1.6)$.

There was a significant difference in the hospital stay among the two groups, the longest hospital stay occurred in conventional hysterectomy group (63.8 \pm 5.7 hours) versus laparoscopic hysterectomy group (20.7 \pm 2.5 hours).also a significant difference was observed in first bowel movement in both groups, the faster occur in laparoscopic hysterectomy group (16.2 \pm 2.4 hours) versus conventional hysterectomy group (19.8 \pm 6.7 hours). 


\begin{tabular}{|l|c|c|c||}
\hline Group of hysterectomy & $\begin{array}{c}\text { conventional } \\
\text { hysterectomy }\end{array}$ & $\begin{array}{c}\text { laparoscopic } \\
\text { hysterectomy }\end{array}$ & P value \\
\hline Age (years) Mean $\mathbf{\text { SD }}$ & $48.7 \pm 3.9$ & $48.5 \pm 4.1$ & 0.86 \\
\hline Parity & $3.1+2.1$ & $3.5+2.8$ & 0.75 \\
\hline BMI (kg/m2) Mean \pm SD & $29.8 \pm 1.4$ & $34.3 \pm 1.3$ & $<0.001^{*}$ \\
\hline $\begin{array}{l}\text { Previous abdominal surgery including } \\
\text { caesarean section }\end{array}$ & 2 & 1 & 0.97 \\
\hline
\end{tabular}

*Statistically highly significant difference $(\mathrm{P} \leq 0.001) \mathrm{Kg}$ : kilogram

Table 1: The preoperative demographic data for all of our patients.

\begin{tabular}{|l|c|c|c|c|c|c||}
\hline \multirow{2}{*}{ Group of hysterectomy } & \multicolumn{2}{|c|}{$\begin{array}{c}\text { conventional } \\
\text { hysterectomy }\end{array}$} & \multicolumn{2}{c|}{$\begin{array}{c}\text { laparoscopic } \\
\text { hysterectomy }\end{array}$} & \multicolumn{2}{c|}{ Total } \\
\cline { 2 - 7 } & No & $\%$ & No & $\%$ & No & $\%$ \\
\hline Fibroid & 42 & 70 & 40 & 66.6 & 82 & 68.3 \\
\hline Adenomyosis & 6 & 10 & 10 & 16.6 & 16 & 13.3 \\
\hline DUB & 8 & 13.3 & 4 & 6.6 & 12 & 10 \\
\hline Endometrial hyperplasia & 4 & 6.6 & 6 & 10 & 10 & 8.3 \\
\hline
\end{tabular}

DUB: dysfunctional uterine bleeding No: number.

Table 2: Frequency distribution of different indications of hysterectomy in both groups according to histopathology.

\begin{tabular}{|c|c|c|c|}
\hline Variable & $\begin{array}{c}\text { conventional } \\
\text { hysterectomy }\end{array}$ & $\begin{array}{c}\text { laparoscopic } \\
\text { hysterectomy }\end{array}$ & P value \\
\hline US length (cm) Mean + SD & $12.90 \pm 1.42$ & $13.42 \pm 2.7$ & 0.71 \\
\hline US width (cm) Mean \pm SD & $9.77 \pm 0.9$ & $10.24 \pm 0.7$ & 0.54 \\
\hline US AP (cm) Mean \pm SD & $8.75 \pm 0.4$ & $9.12 \pm 0.6$ & 0.23 \\
\hline US estimated weight (gm) & $474.5 \pm 192.7$ & $454.5 \pm 172.7$ & 0.45 \\
\hline
\end{tabular}

US: Ultrasound, SD: standard deviation, cm centimeter, gm: gram.

Table 3: Ultrasound variables of studied patient.

\begin{tabular}{|l|c|c|c|}
\hline & $\begin{array}{c}\text { conventional } \\
\text { hysterectomy }\end{array}$ & $\begin{array}{c}\text { laparoscopic } \\
\text { hysterectomy }\end{array}$ & P value \\
\hline Operative time (minutes) Mean \pm SD & $84.7 \pm 9.9$ & $77.3 \pm 7.8$ & 0.15 \\
\hline Blood loss $(\mathbf{m l})$ Mean \pm SD & $170.3 \pm 54.4$ & $110.1 \pm 30.8$ & $<0.001^{*}$ \\
\hline Hb Drop $(\mathbf{g m} / \mathbf{d L})$ mean \pm SD & $1.4 \pm 0.9 \mathrm{gm} / \mathrm{dl}$ & $0.7 \pm 0.2 \mathrm{gm} / \mathrm{dl}$ & $<0.001^{*}$ \\
\hline \multicolumn{1}{|c|}{ Intraoperative blood transfusion } & 0 & 1 & 0.49 \\
\hline
\end{tabular}




\begin{tabular}{|c|c|c|c||}
\hline & $\begin{array}{c}\text { conventional } \\
\text { hysterectomy }\end{array}$ & $\begin{array}{c}\text { laparoscopic } \\
\text { hysterectomy }\end{array}$ & P value \\
\hline Ureteral injury & $0(0)$ & $2(0.03)$ & 0.49 \\
\hline Bladder injury & $2(0.03)$ & $0(0)$ & 0.49 \\
\hline Ileus & $2(0.03)$ & $0(0)$ & 0.49 \\
\hline Pelvic and abdominal wall Haematoma & $0(0)$ & $2(0.03)$ & 0.49 \\
\hline Postoperative febrile morbidity & $10(0.16)$ & $2(0.03)$ & 0.15 \\
\hline Vaginal stump infection & $2(0.03)$ & $0(0)$ & 0.49 \\
\hline Wound seroma and infection & $6(0.13)$ & $0(0)$ & 0.24 \\
\hline Total number of complication & $22(0.43)$ & $6(0.1)$ & 0.02 \\
\hline
\end{tabular}

HB: hemoglobin, ml: milliliter, SD: standard deviation, gm : gram, dl: deciliter.

*Statistically highly significant difference $(\mathrm{P} \leq 0.001)$

Table 4: Ooperative details of hysterectomy (conventional hysterectomy vs. laparoscopic hysterectomy) for enlarged uterus.

\begin{tabular}{|c|c|c|c|}
\hline & $\begin{array}{c}\text { conventional } \\
\text { hysterectomy }\end{array}$ & $\begin{array}{c}\text { laparoscopic } \\
\text { hysterectomy }\end{array}$ & P value \\
\hline $\begin{array}{c}\text { Hospital stay (hours) Mean } \pm \\
\text { SD }\end{array}$ & $63.8 \pm 5.7$ & $20.7 \pm 2.5$ & $<0.001^{*}$ \\
\hline $\begin{array}{c}\text { Bowel movements (hours) } \\
\text { Mean } \pm \text { SD }\end{array}$ & $19.8 \pm 6.7$ & $16.2 \pm 2.4$ & $<0.001^{*}$ \\
\hline $\begin{array}{c}\text { Pain score } \\
\text { Mean } \pm \text { SD }\end{array}$ & $5.2 \pm 1.1$ & $3.8 \pm 1.6$ & $<0.001^{*}$ \\
\hline
\end{tabular}

SD: standard deviation. *Statistically highly significant difference $(\mathrm{P} \leq 0.001)$

Table 5: Hospital stay, bowel movement and pain score in studied group.

Discussion:

Hysterectomy is one of the most common gynecologic surgical procedures in the United States. It ranks second after cesarean section, with around 600,000 procedures performed each year for various indications. [11] Despite the advances of laparoscopic techniques, the majority of hysterectomies are still being done by the abdominal route $(54.2 \%)$ or the vaginal route $(19.7 \%)$. Use of laparoscopic hysterectomy has increased in the last 20 years, accounted for $13.6 \%$ of all hysterectomies in 2010. [12].

Most studies compared the laparoscopic approach to either the standard laparotomy approach or the vaginal route, result in the laparoscopic approach has been widely accepted as an alternative to standard laparotomy [13].

Each approach has its advantages, disadvantages, and limitations. One of the main limitations of laparoscopic approach of hysterectomy is uterine size larger than 12 weeks. With regression of clinical skills of examination and progress of ultrasound machine leading to replacement of uterine size by uterine weight for definition of enlarged uterus. [14]

There is no consensus on which uterine weight should be accepted as indicating a 'large uterus' Different cut-off values of uterine weight have been accepted in different studies. O'Hanlan et al., ( 2011) used 250 gm as a cut-off value; Yavuzcan et al. (2014) used 280 gm Chiu LH et al., (2015) used $300 \mathrm{gm}$ and Smorgick et al., (2013) used $500 \mathrm{gm}$ Uccella S, Cromi A et al., (2014) suggested that the term 'enlarged uteri' should be used for uteruses $>1000 \mathrm{gm}$. We used a cut-off value of $\geq 280 \mathrm{gm}$ according to our facilities and experience and analyzed our data accordingly $[13,15,14,16,17]$.

There is scant information in the literature regarding the optimal surgical management, the associated morbidity and the outcomes of laparoscopic hysterectomy in case of enlarged uteri. However, apart from isolated case reports or limited case series [17,18 19].

It is common experience that in the everyday clinical setting such big uteri are almost invariably removed by large abdominal incisions. There is no doubt that patients would not chose the abdominal route if they were presented with an alternative that eliminates abdominal wound complications and leaves no visible scars. The low rate of laparoscopic hysterectomies in the Egypt is primarily due to the limited equipment, skills, experience (long learning curve).

The present study we tried to find out that laparoscopic hysterectomy is feasible and safe even in case of enlarged uteri weighing > 280 grams, and that a policy of increasing implementation of laparoscopic approach in this setting is associated with a reduction in terms of blood loss, post- 
operative hospital stay and peri-operative adverse events. All operations were performed by the same surgeons and using the same technique.

Obesity and co morbidities associated with it are well known factors that negatively affect surgical outcomes. Since higher BMI is a predisposing factor for abnormal uterine bleeding, endometrial hyperplasia, adenomyosis, and so forth, many females of higher BMI may require hysterectomy. In the past, laparoscopy was technically considered challenging in obese patients and was often considered a relative contraindication. But with significant advances in laparoscopic techniques this has come under review [20].

In this study we found there are significant differences in BMI with laparoscopic hysterectomy group having the highest BMI compared to conventional hysterectomy, as the mean of BMI was $29.8 \pm 1.4 \mathrm{~kg} / \mathrm{m} 2$. and laparoscopic hysterectomy group, the mean of BMI was $34.3 \pm 1.3 \mathrm{~kg} / \mathrm{m} 2$ which nearest $35 \mathrm{~kg} / \mathrm{m} 2$ so high BMI is not consider as one of main obstacle in TLH even in enlarged sized uteri.

In this study, the Mean operating time was slightly but not significally lower in laparoscopic hysterectomy group $77.3 \pm 7.8$ than conventional hysterectomy group $84.7 \pm 9.9$.however we observe Operative time of laparoscopic group showed considerable improvement with repetition of cases and progression in learning curve allover study.

The operative time of the laparoscopy group showed a wide variation among different authors. The mean operative time in our study was similar to that reported by (70 minutes) with uterus weighting over than $300 \mathrm{gm}$. On the other hand, it was shorter than that reported by reported that operating times (109 minutes), Median operative time was longer in the laparoscopic group (139 minutes) however uterine weight in this study larger than $1000 \mathrm{gm}$. The shorter duration of laparoscopic group in this study explained using LigaSure vascular sealing system this preserved considerable time in comparison to the traditional ligation of the pedicles and vessels in conventional method [15, 21, 22].

There was highly significant difference in the estimated blood loss among the two groups with laparoscopic hysterectomy group having the least blood loss $(110.1 \pm 30.8 \mathrm{ml})$ in comparison to conventional hysterectomy group have blood loss $(170 \pm 54.4)$. This significant reduction in blood loss was also reported in most of studies on this literature as in This was explained by pneumoperitoneum compressing microcirculation, better visualization and magnification of smaller vessels added to the usage of LigaSure vascular sealing system [22].

As a consequence of reduced blood loss, the mean Hemoglobin decline 24 hours after surgery was significantly lower in the laparoscopic hysterectomy group $(0.7 \pm 0.2)$ compared to the conventional hysterectomy group $(1.4 \pm 0.9)$. This was confirmed in many other studies as in $[15,22]$.

The mean duration of first bowel movement postoperative in laparoscopic hysterectomy group was significantly lower than in conventional hysterectomy group. That significant difference could be explained by less intestinal manipulation, less exposure to dryness. The mean time of hospital stay in the laparoscopic hysterectomy group was significantly lower than in conventional hysterectomy group. Although that significant difference was reported in almost all studies in literature as [22, 17, 21].
As regard the total incidence of intra-operative and postoperative complication of patient submitted to laparoscopic hysterectomy lower than conventional hysterectomy group but not statically significantly. similar to finding in $[21,23]$.

The patient submitted to laparoscopic hysterectomy group for enlarged uterus . There were one patient had left ureteral injury discovered postoperatively in day 5 double $\mathrm{J}$ ureteric stent inserted by cystoscopy then removed after two month after complete healing without any complication, abdominal wall hematoma in right ancillary port which resolved conservative and one patient had postoperative febrile morbidity in other side conventional hysterectomy group one patient had bladder injury (During pushing the bladder flap downwards, the injury discovered and repair was done immediately with folly's catheter insertion for ten days with good healing.) ileus and vaginal stump infection, three patient of wound seroma and infection, five patient with postoperative febrile morbidity.

Conclusion:

Total laparoscopic hysterectomy with LigaSure is a suitable effective technique alternative to traditional abdominal hysterectomy when the surgical team is sufficiently trained and experienced in managing complications. However more studies are necessary before this technique can become routinely applicable.

\section{References:}

1. Whiteman MK, Hillis SD, Jamieson DJ, et al., (2008) Inpatient hysterectomy surveillance in the United States, 2000-2004. Am J ObstetGynecol 198:1-7.

2. Garry R. (2005) The future of hysterectomy. BJOG. 2005; 112:133-139.

3. Clayton RD (2006) Hysterectomy: Best practice and research. Clin Obstet Gynecol; 20: 1-15.

4. Uccella S, Cromi A, Bogani G, Casarin J, et al., (2013) Systematic implementation of laparoscopic hysterectomy independently of uterus size: actual clinical impact. J Minim Invasive Gynecol. 20:505-516.

5. Kohler C, Hasenbein K, Klemm P, et al., (2003) Laparoscopic assisted vaginal hysterectomy with lateral transaction of the uterine. vessels. SurgEndosc 17:485490.

6. Chang WC. (2008) Successful laparoscopically assisted vaginal hysterectomies for large uteri of various sizes. Acta Obstetricia et Gynecologica 2008; 87:558-563

7. Wang C, Yeung, L, Yen C, et al., (2005) Comparison of the efficacy of the pulsed bipolar system and conventional bipolar electrosurgery in laparoscopically assisted vaginal hysterectomy. J Laparoendosc Adv Surg Tech; 15: 361364.

8. Kung FT, Chang SY. (1996). The relationship between ultrasonic volume and actual weight of pathologic uterus. Gynecol Obstet Invest 42:35-38.

9. Myles PS (2001) Brady arrhythmias and Laparoscopy: a prospective Study of heart rate change with Laparoscopy. Aust. N.Z. J. Obstet. Gynecol; 31:171-3. 11:87-93. 
10. Doyen, E. (1920) In: Spencer-Browne H (ed.). Surgical therapeutics and operative technique, English edition. Toronto: MacMillan Co; 3: 649.

11. Gendy R, Walsh CA, Walsh SR, et al (2011) Vaginal hysterectomy versus total laparoscopic hysterectomy for benign disease: a meta analysis of randomized controlled trials. Am J Obstet Gynecol ; 204(388): 11-18

12. Wright JD, Herzog TJ, Tsui J, et al., (2013) Nationwide trends in the performance of inpatient hysterectomy in the United States. Obstet Gynecol; 122:233-241.

13. Chiu LH, Chen CH, Tu PC, et al., (2015) Comparison of robotic surgery and laparoscopy to perform total hysterectomy with pelvic adhesions or large uterus. J Minim Access Surg

14. Yavuzcan A, Cağlar M, Ustün Y, et al., (2014) Evaluation of the outcomes of laparoscopic hysterectomy for normal and enlarged uterus $(>280 \mathrm{~g})$. Arch Gynecol Obstet 289:831-837.

15. O'Hanlan KA,McCutcheon SP, and McCutcheon JG. (2011) Laparoscopic hysterectomy: impact of uterine size. J Minim Invasive Gynecol 18:85-91.

16. Smorgick N, Dalton VK, Patzkowsky KE, et al., (2013) Comparison of 2 minimally invasive routes for hysterectomy of large uteri. Int $\mathbf{J}$ Gynaecol Obstet 122:128-131.

17. Uccella S, Cromi A, Serati M, et al., (2014) Laparoscopic hysterectomy in case of uteri weighing $\geq 1$ kilogram: a series of 71 cases and review of the literature. J Minim Invasive Gynecol 21: 460-465.

18. Ceccaroni M, Roviglione G, Pesci A, et al., (2014) Total laparoscopic hysterectomy of very enlarged uterus (3030 $\mathrm{g})$ : case report and review of the literature. Wideochir Inne Tech Maloinwazyjne. 9(2):302- 307.

19. Zeng W, Chen L, Du W, et al., (2015) Laparoscopic hysterectomy of large uteri using three-trocar technique. Int J Clin Exp Med. 8:6319-26

20. Osler M., Daugbjerg S., Frederiksen B. L., et al., (2011) Body mass and risk of complications after hysterectomy on benign indications. Human Reproduction. 26(6):15121518.

21. Hasan Terzi, Pinar Solmaz Hasdemir, Alper Biler, et al., (2016) total laparoscopic hysterectomy in patients with enlarged uteruses 9:125-130.
This work is licensed under Creative Commons Attribution 4.0 License

\section{To Submit Your Article Click Here: Submit Article}

DOI:10.31579/2642-9756/018
Ready to submit your research? Choose Auctores and benefit from:

* fast, convenient online submission

* rigorous peer review by experienced research in your field

* rapid publication on acceptance

* authors retain copyrights

* unique DOI for all articles

* immediate, unrestricted online access

At Auctores, research is always in progress.

Learn more https://www.auctoresonline.org/journals/women-healthcare-and-issues 